\title{
Real-time PCR detection of Moritella viscosa, the likely causal agent of winter-ulcer in Atlantic salmon Salmo salar and rainbow trout Oncorhynchus mykiss
}

\author{
S. Grove ${ }^{1, *}$, L. J. $\operatorname{Reitan}^{1}$, T. Lunder ${ }^{2}$, D. Colquhoun ${ }^{1}$ \\ ${ }^{1}$ National Veterinary Institute, PO Box 8156 Dep, 0033 Oslo, Norway \\ ${ }^{2}$ ScanVacc AS, PO Box 233, 2151 Årnes, Norway
}

\begin{abstract}
We report the development of a real-time PCR protocol for specific detection of Moritella viscosa. This bacterium is considered to be the main aetiological agent in development of winter-ulcer, a disease severely affecting salmonid aquaculture in Norway. From a newly elaborated draft version of the genome of $M$. viscosa, the tonB gene sequence was selected as a suitable basis for the development of the real-time PCR assay. The real-time PCR demonstrated the presence of $M$. viscosa DNA sequences in $88.1 \%$ of samples collected from 35 outbreaks of winter-ulcer in Norwegian fish farms. In contrast, standard culturing on blood agar identified $M$. viscosa in only $39.7 \%$ of fish. While the culturing method revealed a similar prevalence (26 to $27 \%$ ) of $M$. viscosa in kidney and ulcer samples, substantially more ulcer $(81.5 \%)$ than kidney $(49.7 \%)$ samples were shown positive by real-time PCR.
\end{abstract}

KEY WORDS: Moritella viscosa $\cdot$ Winter-ulcer $\cdot$ Aquaculture $\cdot$ Salmonids $\cdot$ Norway $\cdot$ Real-time PCR

\section{INTRODUCTION}

Moritella viscosa (ex. Vibrio viscosus; Benediktsdóttir et al. 2000, Lunder et al. 2000) is a psychrotropic Gram-negative, motile bacterium belonging to the family Alteromonadales (NCBI Taxonomy Homepage www.ncbi.nlm.nih.gov/Taxonomy/). In Norway, the bacterium is routinely isolated from farmed Atlantic salmon Salmo salar and rainbow trout Oncorhynchus mykiss suffering from 'winter-ulcer', and the bacterium is believed to be the dominating aetiological agent for this disease (Lunder et al. 1995, 2000). In addition to salmonids, $M$. viscosa has been isolated from Atlantic cod Gadus morhua (Colquhoun et al. 2004) and wild-caught plaice Pleuronectes platessa kept in captivity (Lunder et al. 2000). In experimental challenges, turbot Scopthtalmus maximus and to a lesser degree Atlantic halibut Hippoglossus hippoglossus were susceptible to $M$. viscosa infection (Bjornsdot- tir et al. 2004, Gudmundsdottir et al. 2006). Winterulcer is associated with low water temperatures $\left(<8^{\circ} \mathrm{C}\right)$ and primarily manifests as external skin and muscle lesions of varying severity. However, gill pallor, fin rot and severe internal pathology may also be observed. Commercial vaccines against $M$. viscosa were first introduced in 1993, and an estimated 90 to $95 \%$ of all fish transferred to sea are now vaccinated with vaccines containing an M. viscosa component. However, despite extensive vaccination, mortalities may be high, and when combined with a reduced market quality of the surviving fish, the disease is a major cause of economic losses in Norwegian aquaculture (The health situation in farmed fish in Norway 2007, www.vetinst.no/eng/Research/Publications/FishHealth-Report/Farmed-Fish-Health-Report-2007).

Currently, diagnostic demonstration of Moritella viscosa relies on culture on agar supplemented with $2 \%$ $\mathrm{NaCl}$, a procedure that is often considered unreliable. 
Due to relatively slow growth, $M$. viscosa may be outcompeted by other bacterial species, leading to a possible underestimation of the prevalence of $M$. viscosa (Benediktsdottir et al. 1998, Bjornsdottir et al. 2004).

Here we report the development of a real-time PCR protocol specific for Moritella viscosa. The real-time PCR was used to assess the prevalence of $M$. viscosa in farmed Atlantic salmon and rainbow trout sampled from 35 outbreaks of winter-ulcer along the Norwegian coast during the period 2005 to 2007 .

\section{MATERIALS AND METHODS}

PCR design. Moritella viscosa type strain (NCIMB 13584) was cultured in modified Guz medium (2\% w/v yeast extract, $4.2 \mathrm{mM} \mathrm{MgSO}_{4} \times 7 \mathrm{H}_{2} \mathrm{O}, 11.5 \mathrm{mM}$ $\mathrm{K}_{2} \mathrm{HPO}_{4}, 0.34 \mathrm{M} \mathrm{NaCl}, \mathrm{pH} 7.3$ ) at $7^{\circ} \mathrm{C}$ for $48 \mathrm{~h}$. The bacterium was pelleted by standard centrifugation, and total DNA was isolated from the pellet using a DNeasy kit (69504, Qiagen) according to the manufacturer's instructions. The concentration of isolated DNA was measured using a NanoDrop ND-1000 Spectrophotometer (NanoDrop Technologies). The DNA was shipped on dry ice to 454 Life Sciences, where the $M$. viscosa genome was sequenced and assembled into contigs. Large contigs were annotated using the internet based BAsys automatic annotation service (Van Domselaar et al. 2005). Genes identified by BAsys annotation were manually inspected and verified by standard sequencing and Blast analysis (Altschul et al. 1997; www.ncbi.nlm.nih.gov/BLAST/). Sequencing was performed using a BigDye terminator v3.1 cycle sequencing kit (4337457, Applied Biosystems) and ABI Prism 3130XL-Avant Genetic Analyzer (Applied Biosystems) using 30 cycles of $96^{\circ} \mathrm{C}$ for $10 \mathrm{~s}, 50^{\circ} \mathrm{C}$ for $15 \mathrm{~s}$ and $60^{\circ} \mathrm{C}$ for $4 \mathrm{~min}$, respectively. The ton $B$ gene (GenBank EU332345) was the selected target for design of an $M$. viscosa-specific PCR protocol as described below.

DNA was isolated as described above from a number of Moritella viscosa isolates and from the very closely

Table 1. Primers and probes. All primers and probes were supplied by TAG Copenhagen A/S

\begin{tabular}{|lll|}
\hline Name & Function & 5'-3' Sequence \\
\hline tonB-5'F & Sequencing primer & TGGATGGTGGATAACGGC \\
tonB-3'R & Sequencing primer & CTTTGGCTGGTACTTCCA \\
Mv-tonB-L1 & PCR primer & CGTTGCGAATGCAGAGGT \\
Mv-tonB-R1 & PCR primer & AGGCATTGCTTGCTGGTTA \\
Mv-tonB-Pr & Double-dye probe & TGCAGGCAAGCCAACTTCGACA \\
a'-bound reporter dye: FAM. 3'-bound quencher: Black Hole Quencher 1 \\
\hline
\end{tabular}

related yet non-pathogenic $M$. marina (NCIMB 1144). The ton $B$ gene sequence was then sequenced from each $M$. viscosa isolate and $M$. marina using the primers tonB-5'F and tonB-3'R (Table 1). The $M$. viscosa isolates originated from clinical winter ulcer outbreaks along the Norwegian coast and from Atlantic salmon, rainbow trout and Atlantic cod. The tonB sequences were aligned using ClustalW (EMBL-EBI; www.ebi.ac.uk/Tools/clustalw/index.html), and the produced alignment was employed to identify sequence stretches that were conserved between all examined $M$. viscosa isolates and different in $M$. marina. Accordingly, primers (Mv-tonB-L1 and MvtonB-R1) and a double-dye probe (Mv-tonB-Pr) were designed to be specific for $M$. viscosa (Table 1), generating a PCR amplicon of $133 \mathrm{bp}$.

Real-time PCR was performed using the Stratagene Mx3005P kit and the Platinum Quantitative PCR SuperMix-UDG kit (11730-025, Invitrogen) according to the manufacturers' instructions. The reactions were performed in a total volume of $15.0 \mu \mathrm{l}$, including $4.0 \mu \mathrm{l}$ of sample. An optimised PCR reaction mixture was found to contain $50 \%$ v/v Platinum Quantitative PCR SuperMix-UDG, $6 \mathrm{mM} \mathrm{MgCl}_{2}, 0.33 \mu \mathrm{M}$ of each primer, $0.5 \mu \mathrm{M}$ of double-dye probe and $50 \mathrm{nM}$ ROX. Thermocycling was conducted as follows: $50^{\circ} \mathrm{C}$ for $2 \mathrm{~min}, 95^{\circ} \mathrm{C}$ for $2 \mathrm{~min}$, followed by 40 repetitions of a 2 step temperature cycle $\left(95^{\circ} \mathrm{C}, 15 \mathrm{~s} ; 60^{\circ} \mathrm{C}, 30 \mathrm{~s}\right)$. Water was used as a negative control.

Specificity and sensitivity testing. To verify that positive PCR products would not arise from amplification of DNA/RNA from known pathogens, a broad array of bacterial fish pathogens was tested (Appendix 1). DNA was isolated as previously described and analysed by real-time PCR.

The assay sensitivity, defined as the smallest detectable concentration of Moritella viscosa DNA, was evaluated both for isolated $M$. viscosa DNA and for tissue samples spiked with isolated $M$. viscosa DNA. For isolated $M$. viscosa type strain DNA, a series of 2fold dilutions was prepared, and real-time PCR was subsequently performed in the presence of $1.048 \mu \mathrm{g}$ to $2.56 \times 10^{-9} \mu \mathrm{g}$ DNA per reaction. Each dilution was analysed in 3 parallels. The lower detection limit was defined as the lowest amount of $M$. viscosa DNA that was detected in all 3 parallel reactions. For tissues spiked with isolated $M$. viscosa DNA, aliquots of $100 \mu$ l of head kidney or muscle tissue lysate were spiked with decreasing amounts (2-fold dilution) of isolated $M$. viscosa DNA (i.e. from $4.17 \times 10^{-1} \mu \mathrm{g}$ to $\left.3.1 \times 10^{-6} \mu \mathrm{g}\right)$. Total DNA was then isolated from the 


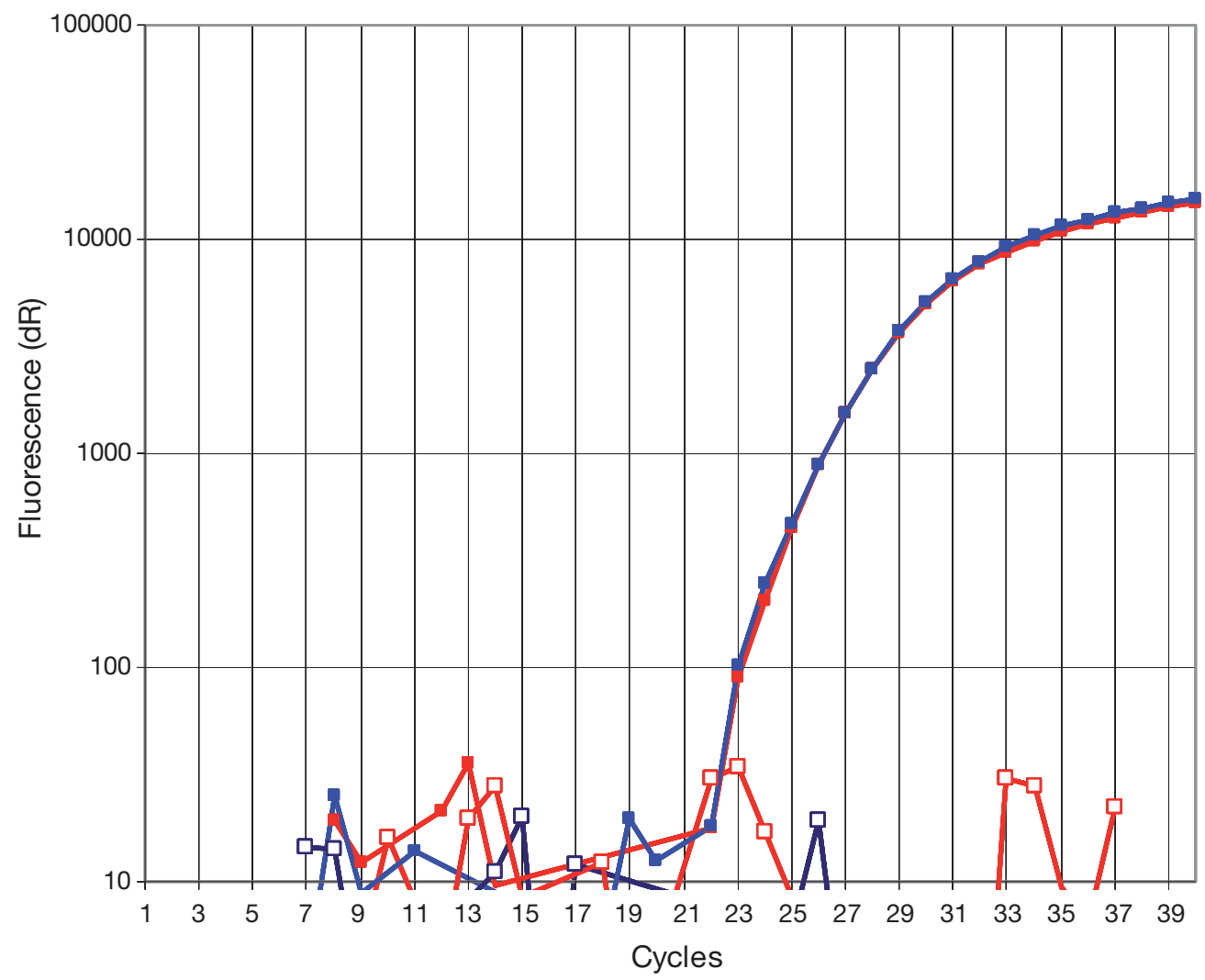

Fig. 1. Moritella viscosa and M. marina. Amplification plot from real-time PCR testing. Real-time PCR of DNA isolated from the $M$. viscosa type strain $(\mathrm{n}=2)$ resulted in significant amplification and fluorescence $(\backsim,-)$. No amplification products or fluorescence could be detected when $M$. marina DNA $(\mathrm{n}=2)$ was PCR tested $(\square, \square)$

spiked tissue aliquots by the NucliSens easyMAG platform as described below in 'Sample preparation for PCR'. From head kidney lysate aliquots, each originating from $1.8 \mathrm{mg}$ of tissue, a mean of $4.9 \mu \mathrm{g}$ total DNA was isolated (range 4.6 to $5.3 \mu \mathrm{g}$ ), and from muscle lysate aliquots (6.5 mg tissue) a mean of $1.8 \mu \mathrm{g}$ total DNA was isolated (range 1.6 to $2.0 \mu \mathrm{g}$ ). For both kidney and muscle, the amount of isolated total DNA was independent of the amount of $M$. viscosa DNA spiked to the aliquots before DNA isolation.

Sample collection. Samples were collected during winter and spring of 2006 and 2007, from 35 outbreaks of clinical winter-ulcer in farmed Atlantic salmon and rainbow trout along the Norwegian coast. The severity of ulcers/abscesses varied considerably between outbreaks and individual fish, from small wounds with almost intact muscle texture to very large wounds with completely necrotised muscle tissue. From each site, 5 freshly dead or moribund fish were sampled and sent on ice to the laboratory by overnight transport. Bacteriological samples from kidney and surface ulcers or abscesses were sown onto heart infusion agar (Difco) containing $2 \% \mathrm{NaCl}$ and $5 \%$ bovine blood (BA), incubated at $15^{\circ} \mathrm{C}$ and initially read after $48 \mathrm{~h}$ (Benedikts- dottir et al. 2000, Lunder et al. 2000). Incubation and observation was extended for a further $5 \mathrm{~d}$.

Sample preparation for PCR. Tissue samples from kidney and surface ulcers or abscesses were dissected and the tissues preserved in RNAlater according to the manufacturer's instructions. Tissue slices corresponding to a volume of approximately $0.03 \mathrm{~cm}^{3}$ were homogenised in $1 \mathrm{ml}$ of lysis buffer. Subsequently, DNA was isolated from $200 \mu \mathrm{l}$ of homogenate using the NucliSens easyMAG platform for total nucleic acid extraction (bioMérieux) by the off-board protocol according to the manufacturer's instructions. Nucleic acids were eluted in $20 \mu$ l of elution buffer.

\section{RESULTS AND DISCUSSION}

Sensitivity. Regarding pure Moritella viscosa DNA, the real-time PCR showed a lower detection limit of approximately $6.09 \times 10^{-14} \mathrm{~g}$ of total $M$. viscosa DNA, equivalent to approximately $10 \mathrm{M}$. viscosa genomes. Although smaller quantities could be detected, these detections were inconsistent. Regarding $M$. viscosa DNA isolated from spiked tissue samples, the real-time 
Table 2. Moritella viscosa. Comparison of results (no. of positive/no. of negative) from real-time PCR versus culture-based detection from kidney and ulcer tissue sampled from fish with clinical winter-ulcer. Pos: positive; neg: negative

\begin{tabular}{|lcrrr|}
\hline \multirow{2}{*}{ Sample } & \multirow{2}{*}{ PCR } & \multicolumn{2}{c}{ Culturing } & \multirow{2}{*}{ Tissue total } \\
& & Pos. & Neg. & \\
\hline Kidney & Pos. & $\mathbf{3 1}$ & $\mathbf{4 4}$ & 75 \\
& Neg. & $\mathbf{1 0}$ & $\mathbf{6 6}$ & 76 \\
Tissue total & & 41 & 110 & 151 \\
Ulcer & Pos. & $\mathbf{3 6}$ & $\mathbf{8 7}$ & 123 \\
& Neg. & $\mathbf{3}$ & $\mathbf{2 5}$ & 28 \\
Tissue total & & 39 & 112 & 151 \\
\hline
\end{tabular}

Table 3. Moritella viscosa. Comparison of detections (no. of positive/no. of negative) in kidney and ulcers/abscesses analysed by either real-time PCR or culture on blood agar supplemented with $2 \% \mathrm{NaCl}$. Pos: positive; neg: negative

\begin{tabular}{|lcrrr|}
\hline \multirow{2}{*}{$\begin{array}{l}\text { Analysis/ } \\
\text { Total }\end{array}$} & \multirow{2}{*}{ Ulcer } & \multicolumn{2}{c}{ Kidney } & \multirow{2}{*}{ Total } \\
& & Pos. & Neg. & \\
\hline PCR & Pos. & $\mathbf{6 6}$ & $\mathbf{5 7}$ & 123 \\
& Neg. & $\mathbf{9}$ & $\mathbf{1 9}$ & 28 \\
Total & & 75 & 76 & 151 \\
Culturing & Pos. & $\mathbf{2 0}$ & $\mathbf{1 9}$ & 39 \\
\multirow{2}{*}{ Total } & Neg. & $\mathbf{2 1}$ & $\mathbf{9 1}$ & 112 \\
& & 41 & 110 & 151 \\
\hline
\end{tabular}

PCR showed a lower detection limit of approximately $128 \mathrm{M}$. viscosa genomes. Because of greater variability in the results from spiked tissue samples, arising from variation in the performance of DNA isolation, a higher number of real-time PCR parallels $(n=8)$ were used for this analysis.

Specificity. When tested against DNA isolated from a selection of bacterial species (Appendix 1), the realtime PCR showed no positive reactions, as shown for Moritella marina (Fig. 1). Blast analysis against expressed sequence tag (EST) and nucleotide databases revealed no sequences that could be amplified and recognised by the $M$. viscosa-specific primers and probe.

Frequency of Moritella viscosa in farmed salmonids experiencing winter-ulcers. Real-time PCR and culturing were used to evaluate the frequency of Moritella viscosa in winter ulcer diseased salmonids, collected from fish farms along the Norwegian coast (Tables $2 \& 3$ ). Only fish from which real-time PCR and culturing data that were obtained from both kidney and ulcers were included in the final data set. In important contrast to the culturing method, the real-time PCR may detect $M$. viscosa irrespective of whether the bacterial DNA originates from live or dead bacteria or bacterial remnants including vaccine components.
However, DNA outside protective environments, such as the inside of live bacteria or in oily vaccines, will most likely decay rapidly in the fish host (Grove et al. 2003). Further, in fish receiving vaccine by intraperitoneal injection, $M$. viscosa antigens of vaccine origin should be expected to be retained long-term in tissue of (central) lymphoid organs (Lamers \& De Haas 1985, Brattgjerd \& Evensen 1996) and in the peritoneum (Cox \& Coulter 1997) and not in peripheral nonlymphoid tissues such as skin and superficial muscle. Hence detections of $M$. viscosa DNA in ulcers most likely indicate the presence of $M$. viscosa of nonvaccine origin.

The real-time PCR data identified the presence of Moritella viscosa in kidney and/or ulcer of $88.1 \%$ (133/151) of examined fish. In contrast, culturing demonstrated the presence of $M$. viscosa in only $39.7 \%$ (60/151) of fish examined. Considering the generally high sensitivity of PCR, these differences in detection frequency were in accordance with expectations. Using real-time PCR, we found that $81.5 \%$ (123/151) of the ulcer samples were positive for $M$. viscosa, whereas only $49.7 \%$ (75/151) of the kidney samples were positive. In contrast, agar culture revealed slightly more positives $(27.2 \% ; 41 / 151)$ from kidney than ulcer $(25.8 \%$; 39/151) samples. The observed differences in tissue distribution between the 2 techniques may reflect inhibition of $M$. viscosa during culture by other members of the mixed bacterial flora (most commonly Vibrio wodanis), which are often found in ulcers open to the surrounding environment. This is supported by PCR detection of $M$. viscosa in 5 of 6 fish from which $V$. wodanis was grown in apparently pure culture using standard bacteriological techniques (data not shown). The high frequency of $M$. viscosa in winter-ulcer-diseased fish observed in the present study supports the hypothesis that $M$. viscosa is a primary pathogenic cause of the disease. Currently, knowledge relating to the pathogenesis of $M$. viscosa in relation to winter-ulcer is limited. The real-time PCR developed in our study should be a useful tool in elucidation of the disease process as well as a welcome addition to histology, immunohistochemical techniques and culture, for diagnosis of $M$. viscosa as a cause of winter-ulcer.

Acknowledgements. The skilled technical assistance of Randi Faller is greatly acknowledged. The work was supported by The Research Council of Norway, Grant 174241.

\section{LITERATURE CITED}

Altschul SF, Madden TL, Schaffer AA, Zhang JH and others (1997) Gapped BLAST and PSI-BLAST: a new generation of protein database search programs. Nucleic Acids Res 25:3389-3402 
Benediktsdóttir E, Helgason S, Sigurjónsdóttir H (1998) Vibrio spp. isolated from salmonids with shallow skin lesions and reared at low temperature. J Fish Dis 21:19-28

Benediktsdóttir E, Verdonck L, Spröer C, Helgason S, Swings $\mathrm{J}$ (2000) Characterization of Vibrio viscosus and Vibrio wodanis isolated at different geographical locations: a proposal for reclassification of Vibrio viscosus as Moritella viscosa comb. nov. Int J Syst Evol Microbiol 50:479-488

Björnsdóttir B, Gudmundsdóttir S, Bambir SH, Magnadóttir B, Gudmundsdottir BK (2004) Experimental infection of turbot, Scophthalmus maximus (L.), by Moritella viscosa, vaccination effort and vaccine-induced side-effects. J Fish Dis 27:645-655

Brattgjerd S, Evensen Ø (1996) A sequential light microscopic and ultrastructural study on the uptake and handling of Vibrio salmonicida in phagocytes of the head kidney in experimentally infected Atlantic salmon (Salmo salar L). Vet Pathol 33:55-65

Colquhoun DJ, Hovland H, Hellberg H, Haug T, Nilsen $\mathrm{H}$ (2004) Moritella viscosa isolated from farmed Atlantic cod (Gadus morhua). Bull Eur Assoc Fish Pathol 24:109-114

Cox JC, Coulter AR (1997) Adjuvants - a classification and review of their modes of action. Vaccine 15:248-256

Grove S, Hoie S, Evensen Ø (2003) Distribution and retention of antigens of Aeromonas salmonicida in Atlantic salmon (Salmo salar L.) vaccinated with a $\Delta a r o A$ mutant or formalin-inactivated bacteria in oil-adjuvant. Fish Shellfish Immunol 15:349-358

Gudmundsdóttir BK, Björnsdóttir B, Gudmundsdóttir S, Bambir SH (2006) A comparative study of susceptibility and induced pathology of cod, Gadus morhua (L.), and halibut, Hippoglossus hippoglossus (L.), following experimental infection with Moritella viscosa. J Fish Dis 29:481-487

Lamers CHJ, De Haas MJ (1985) Antigen localization in the lymphoid organs of carp (Cyprinus carpio). Cell Tissue Res 242:491-498

Lunder T, Evensen Ø, Hålstad G, Hastein T (1995) 'Winter ulcer' in the Atlantic salmon Salmo salar. Pathological and bacteriological investigations and transmission experiments. Dis Aquat Org 23:39-49

Lunder T, Sorum H, Holstad G, Steigerwalt AG, Mowinckel P, Brenner DJ (2000) Phenotypic and genotypic characterization of Vibrio viscosus sp. nov. and Vibrio wodanis sp. nov. isolated from Atlantic salmon (Salmo salar) with 'winter ulcer'. Int J Syst Evol Microbiol 50:427-450

Van Domselaar GH, Stothard P, Shrivastava S, Cruz JA and others (2005) BASys: a web server for automated bacterial genome annotation. Nucleic Acids Res 33:W455-W459

Appendix 1. Bacteria tested for cross-reactivity by real-time PCR. None were detected by real-time PCR. All bacterial strains were from the collection at the National Veterinary Institute, Norway

Atypical Aeromonas salmonicida

Aeromonas salmonicida salmonicida

Bacillus cereus

Brochothrix thermosphacta

Carnobacterium piscicola

Francisella philomiragia noatunensis

Escherichia coli

Moritella marina

Mycobacterium marinum

Pasteurella skyensis

Pseudomonas fluorescens

\author{
Piscirickettsia salmonis \\ Rhodococcus erythropolis \\ Staphylococcus aureus \\ Streptococcus agalactiae \\ Tenacibaculum maritimus \\ Vibrio anguillarum $\mathrm{O} 1$ \\ Vibrio salmonicida \\ Vibrio splendidus \\ Vibrio wodanis \\ Yersinia ruckeri
}

Editorial responsibility: Catherine Collins, Aberdeen, UK
Submitted: January 14, 2008; Accepted: July 31, 2008 Proofs received from author(s): October 27, 2008 